\title{
APRENDIZES SURDOS DE LÍNGUA PORTUGUESA (L2) ESCOLA BILÍNGUE PARA INCLUSIVA
}

\author{
Sandra Mara Alves Siqueira ${ }^{1}$ \\ Marília Costa Pessanha Lara ${ }^{2}$
}

\section{RESUMO}

Este artigo apresenta a pesquisa desenvolvida no Trabalho de Conclusão de Curso (SIQUEIRA, 2020) que visou investigar as dificuldades percebidas na transição do estudante surdo do $5^{\circ}$ ano (em escola bilíngue) para o $6^{\circ}$ ano (em escola inclusiva). A pesquisa originou-se a partir do questionamento: Por que alguns estudantes surdos não apresentam a mesma fluência, domínio e o desenvolvimento na língua portuguesa que estudantes ouvintes, mesmo passando por um processo de educação bilíngue? Esta pesquisa tem cunho qualitativo e foi desenvolvida por meio de levantamento bibliográfico no Google Acadêmico, livros e artigos através dos descritores: bilinguismo, inclusão, educação de surdos, história dos surdos, ensino de português e transição de $5^{\circ}$ para o $6^{\circ}$ ano. 0 referencial teórico parte de Sabanai (2006), que apresenta a preocupante situação dos estudantes surdos, em que há defasagem escolar em comparação a aprendizes ouvintes, mesmo sem déficit cognitivo. Stumpf e Wanderley (2016), entre outros, explicam que a Libras é a língua natural dos surdos e a língua portuguesa é uma segunda língua, sendo necessário adaptações metodológicas e recursos adequados para a evolução no processo de ensino-aprendizagem, evitando atrasos ou desistências no prosseguimento dos estudos. Além disso, diferentes marcos legais trazem direitos pertinentes ao educando surdo (Estatuto da Criança e do Adolescente, Decreto 5.626/2005, Política Nacional de Educação Especial). É previsto que, no processo educacional, todas as crianças e adolescentes tenham o direito de ser valorizados em sua cultura, artes e his-

${ }^{7}$ Faculdade UNINA - Licenciada em Letras Libras-Português. E-mail: salvessiqueira4@gmail.com

${ }^{2}$ Faculdade UNINA - Mestre em Letras (Linguística).E-mail: mariliacosta.mcp@gmail.com 
tória. No caso dos surdos, os modelos educacionais atualmente propostos são o modelo bilíngue e o inclusivo. Optou-se por investigar a transição do $5^{\circ}$ para o $6^{\circ}$ ano por ser nessa transição entre etapas da educação básica (EF1 para EF2) que muitas vezes ocorre também a transição entre os dois modelos. Parte da nossa reflexão aqui é como ambos os modelos podem garantir esses direitos ao estudante surdo na transição entre modelos/escolas observada no período selecionado. Concluímos que a escola não deve ser o único ambiente sinalizante da criança, uma vez que a interação familiar pré-escolar é importante para que o estudante chegue à escola com base linguística, assim como a criança ouvinte que chega à escola já usando fluentemente o português. Essa atribuição cabe ao SUS, que deveria exercer esse papel conscientizador quanto à situação linguística da criança surda desde o diagnóstico da surdez.

Palavras-chave: Surdos. Educação bilíngue para surdos. Libras. Inclusão. Política Educacional.

\section{INTRODUÇÃO}

A comunidade surda brasileira defende os direitos educacionais de surdos amparada pela legislação vigente no Basil, mas se verifica que há discrepâncias entre os documentos e a prática realizada nos ambientes de aprendizado. O primeiro direito da criança surda é a utilização da Língua Brasileira de Sinais (LIBRAS)3 ${ }^{3}$ Contudo, constata-se que a maioria das famílias é de pessoas ouvintes que não utilizam essa língua visual. É interessante observar que a responsabilidade de orientar e esclarecer os pais sobre a importância da interação e uso da língua de sinais e da língua portuguesa na modalidade escrita é atribuída ao Sistema Único de Saúde (SUS). Ou seja, a legislação formaliza uma intenção de que a criança surda tenha acesso à linguagem a partir do momento em que alguma perda auditiva é diagnosticada, antes mesmo da idade pré-escolar, para que ocorra seu desenvolvimento em tempo apropriado, beneficiando-a e facilitando seu futuro no convívio social e aprendizado educacional.

Segundo Ellis (1994) apud Gesser (2010, p. 9), língua materna ou primeira língua (L1) é aquela que é aprendida espontaneamente na família, enquan-

\footnotetext{
${ }^{3}$ Decreto Federal n5.625/05, art. 25, VIII.
} 
to a segunda língua (L2) é a que se aprende posteriormente na comunidade mais externa ou em uma instituição de ensino. Assim, considera-se que, para a população surda, a L1 por excelência deveria ser a Libras, uma língua visual que pode ser adquirida de forma espontânea por uma criança que não escuta e não acessa a língua oral sem algum tipo de intermediação. Já a Língua Portuguesa, como língua de comunidade majoritária do Brasil, seria a L2 dessa comunidade. Faz-se primordial a aquisição da L1 como base linguística e o consequente aprendizado da L2 na modalidade escrita. Entretanto, Quadros (1997), Mota (2008), Gesser (2010), Finau (2014), entre outros, explicam que, por situações adversas, os aprendizes surdos chegam ao ensino fundamental I totalmente desprovidos dessa base linguística robusta.

\section{REFERENCIAL TEÓRICO}

Importantes teóricos demonstram que a base comunicativa familiar é essencial, pois conterá o estímulo linguístico desde os primeiros dias de vida, permitindo que ocorra o desenvolvimento cognitivo, a aquisição linguística e comunicacional por meio das interações socioculturais. Segundo Vygotsky (2003) apud Maestri (2014, p. 42), “a linguagem é um instrumento que acontece por meio de signos e cria o pensamento e as funções superiores e, além de formar a comunicação, também elabora o pensamento". Conforme Maestri (2014), a teoria de Vygotsky

É considerada como uma abordagem historicocultural, na qual o processo de conhecimento possui uma dinâmica interativa, ocorrendo na interação do sujeito com o objeto, sempre mediado socialmente (VYGOTSKY, 2003, p. 63). Vygotsky acredita que é na e pela interação humana que ocorre a construção do sujeito, sendo que essas interações acontecem em situações concretas da vida. (MAESTRI, 2004, p. 46)

Entende-se que o desenvolvimento da criança é diretamente dependente da interação familiar e social e, caso esta não ocorra por falta de conhecimento linguístico, poderá acarretar problemas cognitivos.

Chomsky e Lasnik (1991) apud Quadros (1997, p. 27) esclarecem que a aqui- 
sição linguística ocorre a partir de um dispositivo mental inato ao ser humano (logo, extensivo também às pessoas surdas), que é acionado de forma natural a partir de estímulos linguísticos. No caso de surdos, a língua de sinais cumpre essa função sem barreira alguma, por ser visual; já a língua portuguesa jamais poderá prover esse estímulo e acionar a aquisição espontânea pela falta da acuidade auditiva da criança. Também Finau (2014, p. 938) explica que, da mesma maneira, é importante no processo ensino-aprendizado ser primordial ocorrer o bilinguismo diglóssico (a aquisição da Libras como L1 e depois a escrita da Língua Portuguesa como L2).

Para Santana (2004, p. 344), durante a idade crítica na aquisição da linguagem, é relevante o input abundante e rico enquanto o sistema neurológico está imaturo, pois, caso já esteja maduro, será impossível modificá-lo.

Não há dúvida de que o meio ambiente e as interações influenciam diretamente a organização cerebral. A plasticidade cerebral está longe de reduzir-se a fatores meramente neurofisiológicos e bioquímicos. [...] o fator crucial para o desenvolvimento linguístico das crianças não é primariamente o canal sensoriomotor, e, sim, a abundância e a riqueza do input acessível e disponível para a criança durante toda a sua infância. Isso pode ser verificado pela aquisição da língua de sinais em crianças surdas filhas de pais surdos. Nesse caso, o desempenho linguístico é comparável ao da aquisição da língua oral nos ouvintes. [...] Em outras palavras, a comunicação é o "catalisador" da maturação "social". O desenvolvimento da maturação é atrasado em consequência do atraso de desenvolvimento da linguagem. Ou seja, a maturação deixa de ser apenas um fenômeno biológico e, portanto, preestabelecido em uma idade crítica. (SANTANA, 2004, p. 347, grifos nossos.)

De acordo com Lessa-de-Oliveira e Alves (2019, p. 4060), há o período de capacidade da aquisição da linguagem e ele precisa ser ativado no tempo certo, por volta de seis anos e depois na adolescência. Caso isso não ocorra, o aprendiz perde essa capacidade ou diminui as possibilidades de aquisição da L2, conforme pode ser verificado pela citação seguinte. 
Toda propriedade biológica que se conhece tem um período no qual precisa ser ativada; depois desse período, a capacidade de ativação declina acentuadamente ou pode até desaparecer (CHOMSKY, 2008, p. 78). Nesse sentido, o que Chomsky propõe é que, com a linguagem, também seja assim; ele sugere que há uma linha de corte no que diz respeito à capacidade de adquirir a linguagem, por volta dos seis anos e outra na puberdade. Nas palavras de Chomsky, 'essas duas transições restringem, consideravelmente, a capacidade de adquirir uma segunda língua. Quando você passou de certo estágio, até pode adquiri-la, mas normalmente como uma espécie de acréscimo à língua que você já tem. (CHOMSKY, 2008, p. 79).

Ao respeitarmos a língua de sinais dentro do espaço escolar como a base comunicativa entre docentes e estudantes surdos, haverá melhor rendimento no aprendizado, conforme pode ser constatado em Lodi e Lacerda, 2009 apud Lacerda et al. 2013, p. 67.

[...] A língua de sinais é sabidamente língua de constituição de sujeitos surdos (MOURA, 2000), e quando é assumida em espaços educacionais, favorece um melhor desempenho dos alunos surdos (LODI; LACERDA, 2009 apud LACERDA et al. 2013, p. 67).

Esses aspectos relativos à aquisição de linguagem devem ser considerados na formulação das propostas educacionais para crianças surdas, já que se trata de uma questão específica do seu desenvolvimento. No cenário atual brasileiro, identificam-se dois modelos que consideram o uso da língua de sinais e da língua portuguesa: o modelo de escolas bilíngues para surdos e o modelo de educação inclusiva bilíngue. O primeiro modelo (bilíngue) se estrutura a partir do uso da língua de sinais como primeira língua do aprendiz, aquela que intermedeia o ensino como um todo e a aquisição da língua portuguesa como L2. A língua de sinais é utilizada em todos os espaços escolares, reproduzindo na escola um ambiente linguístico rico que provavelmente não ocorre em sua família, considerando-se que a maioria das crianças surdas não tem a família fluente em língua de sinais. Já o segundo (modelo inclusivo) insere a língua de sinais como um suporte específico para a criança surda, através da atuação de um tradutor-intérprete e de adaptações promovidas pelo professor regente. $\bigcirc$ 
ambiente da escola funciona majoritariamente na língua oral. Reconhecemos uma intenção positiva de normalização da deficiência na sociedade como um todo através de escolas com "apreço à diversidade como condição a ser valorizada" (MANTOAN; PRIETO, 2006, p. 40), entretanto esse modelo mostra-se problemático do ponto de vista da aquisição da linguagem. Afinal, não se proporciona um ambiente linguístico acessível para a criança, apenas um apoio adaptativo que só seria eficaz para pessoas que já teriam a língua adquirida e com fluência (é importante lembrar que o tradutor/intérprete não deveria ensinar a língua para a criança).

Segundo Costa (2018, p. 8), é importante que o docente observe o tempo diferenciado que cada estudante necessita na execução de tarefas, crie estratégias para atingir os objetivos de aprendizagem e promova oportunidades de participação com equidade. A autora lembra ainda que o aprendizado deve ser significativo e adequado a cada aprendiz para que usufrua no futuro de tudo que aprendeu. Os aprendizes surdos, ao ingressarem no Ensino Fundamental II, desconhecem a Língua Portuguesa na modalidade escrita L2 e muitas vezes nem conhecem a si próprios identitária e culturalmente. Ademais, vivenciam outros problemas: falta da presença familiar, falta de conhecimento da própria língua materna durante o ciclo I, falta de convívio social com os próprios pares, falta de conhecimento de professores da questão linguística e até mesmo falta de empatia.

Lacerda (2006) apud Góes et al. (2011) declaram que os surdos, apesar de estarem presentes, não são considerados e ainda se cria a falsa imagem de que a inclusão é um sucesso.

Pesquisas apontam que o ensino de surdos é restritivo no que diz respeito aos aspectos linguísticos, sociais, afetivos, de identidade, entre outros, que são desenvolvidos por meio da interação social. O compartilhamento de uma língua é fundamental para que haja a constituição plena dos sujeitos. Caso não ocorra, poderá ocasionar prejuízos no desenvolvimento (LACERDA, 2006, p. 181).

Percebe-se que é de fundamental importância que os alunos surdos frequentem a escola bilíngue, pois, conforme Fernandes (2012, p. 79), terão que 
interagir tanto com outros estudantes surdos como com professores bilíngues ou surdos para a formação verbal de conceitos básicos. Essa ideia também é corroborada por Finau (2014, p. 940), que adverte que, se não houver essa interação em ambientes bilíngues, os surdos poderão ter problemas na construção de frases em Libras e, posteriormente, em Língua Portuguesa. Assim sendo, a criança surda deve frequentar a escola bilíngue para que ocorra a estruturação da Libras como L1 e, a partir daí, ela aprenda a Língua Portuguesa na modalidade escrita L2.

Observou-se, por meio de relatos de estudantes surdos e intérpretes de Libras, que, na região da Grande Curitiba, as escolas que oferecem ensino bilíngue são majoritariamente da pré-escola ao $5^{\circ}$ ano (escolas municipais). Esse modelo oferta aos aprendizes surdos ambas as línguas: a Libras e a Língua Portuguesa. A Libras é utilizada para a comunicação geral entre estudantes e profissionais da educação e a Língua Portuguesa é usada na modalidade escrita, ocorrendo o livre curso nas duas modalidades. Porém, quando o estudante progride em seus estudos e chega ao $6^{\circ}$ ano, as escolas passam a adotar o modelo inclusivo (escolas estaduais); somente a Língua Portuguesa figura no currículo como uma disciplina e a Libras é apenas uma disciplina extracurricular. Alguns surdos sentem dificuldades pelo fato de a língua corrente anteriormente ter sido a Libras, e agora passa a ser a Língua Portuguesa a majoritária. Observa-se que há diferentes leis que regem cada etapa e, consequentemente, há descontinuidade dos modelos educacionais.

Conforme Martins e Silva (2015, p. 4), as escolas de educação bilíngue ensinam a Libras às crianças surdas - L1, e as escolas de educação inclusiva ensinam a Língua Portuguesa - L2; os professores são ouvintes e comunicam-se exclusivamente com a língua oral, dificultando o aprendizado. É necessário que haja uma comunicação comum e, segundo Trenche (1998, p. 11), não existe garantia de que, ao acessar uma escola inclusiva, haja aprendizado, pois a cada estudante surdo que acessa essa escola são geradas novas necessidades e obrigações. A criança surda sofre no período de transição entre o modelo bilíngue e o inclusivo, pois passa a ter diversas disciplinas e vários professores. $\bigcirc$ mesmo ocorre com a criança ouvinte que, anteriormente, no Fundamental I, 
tinha uma única professora e poucas disciplinas. No entanto, há um agravante para o aprendiz surdo que é usuário da Libras como língua nativa, em razão de sua percepção ser viso-espacial, diferente da Língua Portuguesa majoritária, usada na instituição inclusiva, que é oro-auditiva, trazendo barreiras comunicativas e consequentemente o baixo índice de aprendizado do estudante surdo.

\section{CONSIDERAÇÕES FINAIS}

Diante do exposto, observamos que o modelo educacional que melhor ampararia um processo de aquisição bilíngue seria a educação bilíngue para surdos, e não o modelo de inclusão bilíngue. Faz-se necessária a oportunidade de um ambiente linguístico plenamente acessível para a criança surda e operacionalizar isso através de uma política pública educacional nos anos iniciais é uma das formas mais eficazes de amplificar esse processo à sociedade como um todo. Assim, é problemático que uma criança tenha que se desenvolver linguisticamente em um ambiente desfavorável, com a mediação de apenas um adulto, sem interação com pares e em uma estrutura curricular e metodológica que não prioriza sua especificidade linguística.

É compreensível que estudantes que passam pelo modelo inclusivo nos anos iniciais de sua formação não tenham resultados adequados de aquisição de Português e muito menos de Libras, como observa Lacerda (2006). Porém, mesmo quando o estudante tem acesso a uma educação bilíngue, observam-se alguns casos em que chega ao EF2 e ingressa no modelo inclusivo sem domínio da Libras e do Português. A partir de Chomsky (2008), compreende-se que é necessário o input linguístico inicial para que o dispositivo interno natural seja acionado. E, a partir de Vygotsky e Leontiev (2020 (1932)), vemos que, pela interação social e por meio das experiências, ocorre inicialmente a memorização dos signos, antecedendo a estrutura do pensamento. Dessa forma, é importantíssimo que a experiência sinalizante da criança não se restrinja apenas à escola, mas atinja também a família e os outros ambientes de convívio da criança. 
Possível solução seria a criança ter acesso à Libras ou à língua de sinais do país desde cedo (filhos de surdos, filhos de ouvintes que aprendem Libras) ou mesmo apoio ao desenvolvimento da linguagem oral (terapêutico - apoio de uma equipe multidisciplinar: fonoaudiólogo, psicopedagogo). Para isso, é necessário que o SUS (como previsto na legislação) oriente as famílias da criança surda quanto aos possíveis caminhos de desenvolvimento de linguagem, em especial, a via da sinalização. Isso ocorreria através da divulgação e incentivo à matrícula em cursos de Libras, seja em Centros de Apoio ao Surdo, FENEIS, universidades, prefeituras, Associações de Surdos ou outras entidades que os ofertam. Caso seja de interesse da família optar pelo treinamento da fala, há profissionais fonoaudiólogos que sabem a Libras e conhecem a cultura e a identidade surda, podendo promover um atendimento bilíngue.

Considerando que os estudantes chegam à primeira fase do EF sem base na Libras e que, em alguns casos, só são imersos em um ambiente linguístico rico na escola, hipotetizamos que os professores se vejam compelidos a ensinar com maior intensidade a Libras, como mecanismo de suprir essa falta. Assim, os aprendizes surdos chegam ao $6^{\circ}$ ano com defasagem na Língua Portuguesa, mesmo tendo passado por uma proposta supostamente bilíngue. Entende-se que, se a criança surda chegasse ao Ensino Fundamental I com a base linguística bem estruturada, a passagem para o Fundamental II ocorreria com maior tranquilidade, pois o foco do Ensino Fundamental I bilíngue seria efetivamente tanto no ensino da Libras quanto à dedicação no ensino da Língua Portuguesa na modalidade escrita. Assim, o aprendiz surdo chegaria ao $6^{\circ}$ ano mais preparado para adaptar-se na escola inclusiva.

Além do apoio ao uso da Libras pela família e comunidade fora do ambiente escolar, outro suporte importante seria a abertura de creches bilíngues, com professores surdos. As leis preveem a inclusão de crianças de zero a três anos e onze meses nas creches e a partir dos quatro anos na pré-escola, em que é necessário ter contato com professores surdos e pares linguísticos para aprenderem a Libras e a Língua Portuguesa na modalidade escrita, e para isso as escolas bilíngues são mais indicadas.

Embora existam os Tradutores e Intérpretes de Língua de Sinais (TILS) na 
educação inclusiva para interpretar a fala do professor durante a aula e traduzir atividades e provas, ainda será necessária a metodologia apropriada, ou seja, dentro do contexto sociocultural dos surdos. Há docentes que desconhecem as especificidades desses aprendizes que possuem língua, percepção, identidade e cultura particulares ao povo surdo. Pelo fato de haver pouco tempo e diversas necessidades em sala de aula, torna-se um processo difícil para ambos, professor e estudante.

Verificou-se a necessidade de os educadores buscarem conhecimentos na área da surdez para o aprendizado da Libras, bem como envolvimento com a comunidade surda para melhor entender sua cultura e identidade. A esse respeito, uma solução possível seria a promoção de capacitações para pedagogos e professores que atendam estudantes surdos.

\section{REFERÊNCIAS}

BRASIL. Câmara dos Deputados. Decreto n $^{\circ} \mathbf{5 . 6 2 6}$ de 22 de dezembro de 2005. <http://www.planalto.gov.br/ccivil_03/_ato2004-2006/2005/decreto/d5626.htm> Acesso em 13 de jun. de 2020.

BRASIL. Presidência da República. Casa Civil. Subchefia para Assuntos Jurídicos. Lei n 8.069 de 13 de julho de 1990. Estatuto da Criança e do Adolescente (ECA). 1990. <http:// www.planalto.gov.br/ccivil_03/leis//8069.htm>. Acesso 28 de out. de 2020.

COSTA, Maria Tereza. A BNCC e a Educação Inclusiva no Ensino Fundamental / Maria Tereza Costa. - Curitiba, 2018. Material didático da disciplina de A BNCC e a Educação Inclusiva no Ensino Fundamental - Faculdade São Braz (FSB), 2018.

FERNANDES, Sueli. Educação de Surdos. Curitiba, 2012.

FINAU, Rossana. Aquisição de escrita por alunos surdos: a categoria aspectual como um exemplo do processo. Revista Brasileira de Linguística Aplicada, v. 14, n. 4, p. 935-956, 2014.

GÓES, Alexandre Morand et al. Língua Brasileira de Sinais-Libras: uma introdução. 2011.

LACERDA, Cristina Broglia Feitosa. A inclusão escolar de alunos surdos o que dizem alunos, professores e intérpretes sobre esta experiência. Cad. Cedes, Campinas, vol. 26, n. 69, p. 163-184, maio/ago. 2006. 
LACERDA, Cristina Broglia Feitosa de; ALBRES, Neiva de Aquino; DRAGO, Silvana Lucena dos Santos. Política para uma educação bilíngue e inclusiva a alunos surdos no município de São Paulo. Educação e Pesquisa, v. 39, n. 1, p. 65-80, 2013.

LESSA-DE-OLIVEIRA, Adriana Stella Cardoso; ALVES, Marcelo Meira. A categoria tempo na aquisição do português escrito como L2 por surdos. Fórum Linguístico, v. 16, n. 4, p. 4057-4075, 2019.

MAESTRI, Rita de Cássia. História de vida de uma psicóloga e professora surda: mediações, desconstruções e construções. 2014. Dissertação de Mestrado. UFPR.

MANTOAN, Maria Teresa Eglér; PRIETO, Rosângela Gavioli. Inclusão escolar: pontos e contrapontos. Summus. São Paulo / SP. 2006.

MARTINS, Joana Célia do Socorro Gomes de Andrade; da SILVA, Josiel Monteiro. Reflexões sobre Intervenções e Adaptações Curriculares para a Educação de Surdos. Educere XII Congresso Nacional de Educação, Formação de Professores, complexidade e Trabalho Docente, PUCPR 26 a 29/10/2015.

MOTA, Mailce Borges. Aquisição de segunda língua. Universidade Federal de Santa Catarina - UFSC, 2008.

QUADROS, Ronice Müller de. Educação de Surdos: A Aquisição da Linguagem.. Artmed. Porto Alegre. 1997, reimpressão 2008.

SABANAI, Noriko Lúcia. O Aluno Surdo e o Processo de Ensino e Aprendizagem da Língua Portuguesa, na Modalidade Escrita, em um Contexto de uma Educação Bilíngue. 2006.

STUMPF, Marianne Rossi; WANDERLEY, Débora Campos. Quem fala português, escreve em português. Quem fala inglês, escreve em inglês. Os surdos: em que língua escrevem? Revista Letras Raras, v. 5, n. 1, p. 93-107, 2016.

TRENCHE, Maria Cecília Bonini. A inclusão da criança surda no ensino comum. Distúrbios da Comunicação, v. 10, n. 1, 1998.

VYGOTSKY, Lev Semionovitch. LEONTIEV, Aleksei Nikolaievitch. "Prefácio para o livro de A.N. Leontiev O desenvolvimento da memória." Cadernos CEDES 40.111 (2020): $114-122$ 